\title{
Effect of Anti-tuberculosis Drugs on Liver Damage Based on Alanine Aminotransferase Level in Pulmonary Tuberculosis Patients
}

\author{
Vera Dianwari, ${ }^{1}$ Vycke Yunivita Kusumah Dewi, ${ }^{2}$ Nia Kania ${ }^{3}$ \\ ${ }^{1}$ Faculty of Medicine Universitas Padjadjaran, ${ }^{2}$ Department of Pharmacology and Therapy Faculty \\ of Medicine Universitas Padjadjaran, ${ }^{3}$ Department of Anatomy, Cell Biology and Physiology \\ Faculty of Medicine Universitas Padjadjaran
}

\begin{abstract}
Background: Antituberculosis (anti-TB) drugs could cause serious effect such as hepatotoxicity signed by the increase of Alanine Aminotransferase (ALT) level. Anti-TB drugs are still needed by TB patients who have hepatotoxicity, although clinicians who manage this condition have not recognize whether the advantage of anti-TB drugs is higher than its adverse effect, and there is no data describing about that issue. This study was conducted to discover the liver damage based on the ALT changes before and 12 days after initial antiTB treatment.

Methods: This was a cross-sectional study with total sampling of medical records of pulmonary tuberculosis inpatients from 1st January 2013-31th December 2014 at the Department of Internal Medicine of Dr. Hasan Sadikin.General Hospital. From 141 data, only 14 medical records were eligible to be included in this study. The data used were ALT level before and after therapy. These data were analyzed using Wilcoxon test and considered as significant if $\mathrm{p}<0.05$.

Results: The median age of the subject study was 48(18-65) years. Among 14 patients, 8 were female and 6 were male. Five out of fourteen patients developed hepatotoxicity. Four out of five developed grade 1 hepatotoxicity and one out of five developed hepatotoxicity grade 4 . The analysis of the data showed the differences of ALT level before anti-TB therapy (22(4-447)) and 12 days after initial therapy (18.5(4-1206)) was not significant $(\mathrm{p}=0.660)$.
\end{abstract}

Conclusions: There is no liver damage based on ALT changes after anti-TB treatment so the treatment can be continued.

Keywords: Alanine aminotransferase, antituberculosis drugs, hepatotoxicity, tuberculosis

\section{Introduction}

Tuberculosis (TB) is still one of the biggest problems in the world. ${ }^{1,2}$ The World Health Organization (WHO) reported in 2014 that there were approximately 9,6 million new cases of TB, $58 \%$ which occurred in South-East Asia and Western Pacific Region, including Indonesia. ${ }^{2}$

Tuberculosis is actually a disease that can be treated with intensive and comprehensive treatment. ${ }^{3}$ The challenges from this treatment are that antituberculosis (antiTB) drugs could cause multidrug resistance (MDR) and some adverse effects, including hepatotoxicity. Hepatotoxicity is one of the anti-TB drugs adverse effects. ${ }^{3,4}$ It is a liver dysfunction or liver damage that correlates to drug dosage or xenobiotic. ${ }^{5}$ Anti-TB drugs that cause hepatotoxicity include Isoniazid, rifampicin, pyrazinamide, and ethambutol. ${ }^{5}$ Hepatotoxicity could be seen by the high level of alanine aminotransferase (ALT) especially 12 days after initial treatment. ${ }^{6}$ This substance is a specific enzyme produced by the liver when the damage occurred. ${ }^{5}$ Patients with hepatotoxicity still need anti-TB drugs, although physicians have not discovered whether the advantages of anti-TB drugs are higher than the disadvantages. ${ }^{4}$

Correspondence: Vera Dianwari, Faculty of Medicine, Universitas Padjadjaran, Jalan Raya Bandung-Sumedang Km. 21, Jatinangor, Sumedang, West Java, Indonesia, Email: verdian.anwari@gmail.com 
Until currently, there has not been any study comparing the effect of anti-TB drugs as the agent that cause hepatotoxicity to the changes of ALT level in Indonesia, especially in Dr. Hasan Sadikin General Hospital Bandung. These data can help the physician to determine whether the anti-TB drugs treatment should be continued or not when the ALT is increasing. This study was conducted to discover liver damage based on ALT level changes before and 12 days after initial treatment of anti-TB drugs.

\section{Methods}

The study was carried out from SeptemberNovember 2015 at the Department of Internal Medicine and Department of Clinical Pathology in Dr. Hasan Sadikin General Hospital Bandung. It was an observational analytic study with a cross sectional approach using nonprobability total sampling of pulmonary TB in inpatients' medical records from 1st January 2013-31th December 2014. This study was approved by the Health Research Ethics Committee of Dr. Hasan Sadikin General Hospital Bandung and all data collection will be concealed.

The object of this study was the medical record of pulmonary TB patients who had first line anti-TB drugs treatment in Dr. Hasan Sadikin General Hospital Bandung. The inclusion criteria were: (1) the patients age were above 18 years, (2) had first line anti-TB drugs treatment, (2) had ALT examination at least twice, before the treatment and 12 days after treatment. Measurement of ALT was carried out using the Hitachi 902 machine in the Department of Clinical Pathology and the result was attached in the medical record document.

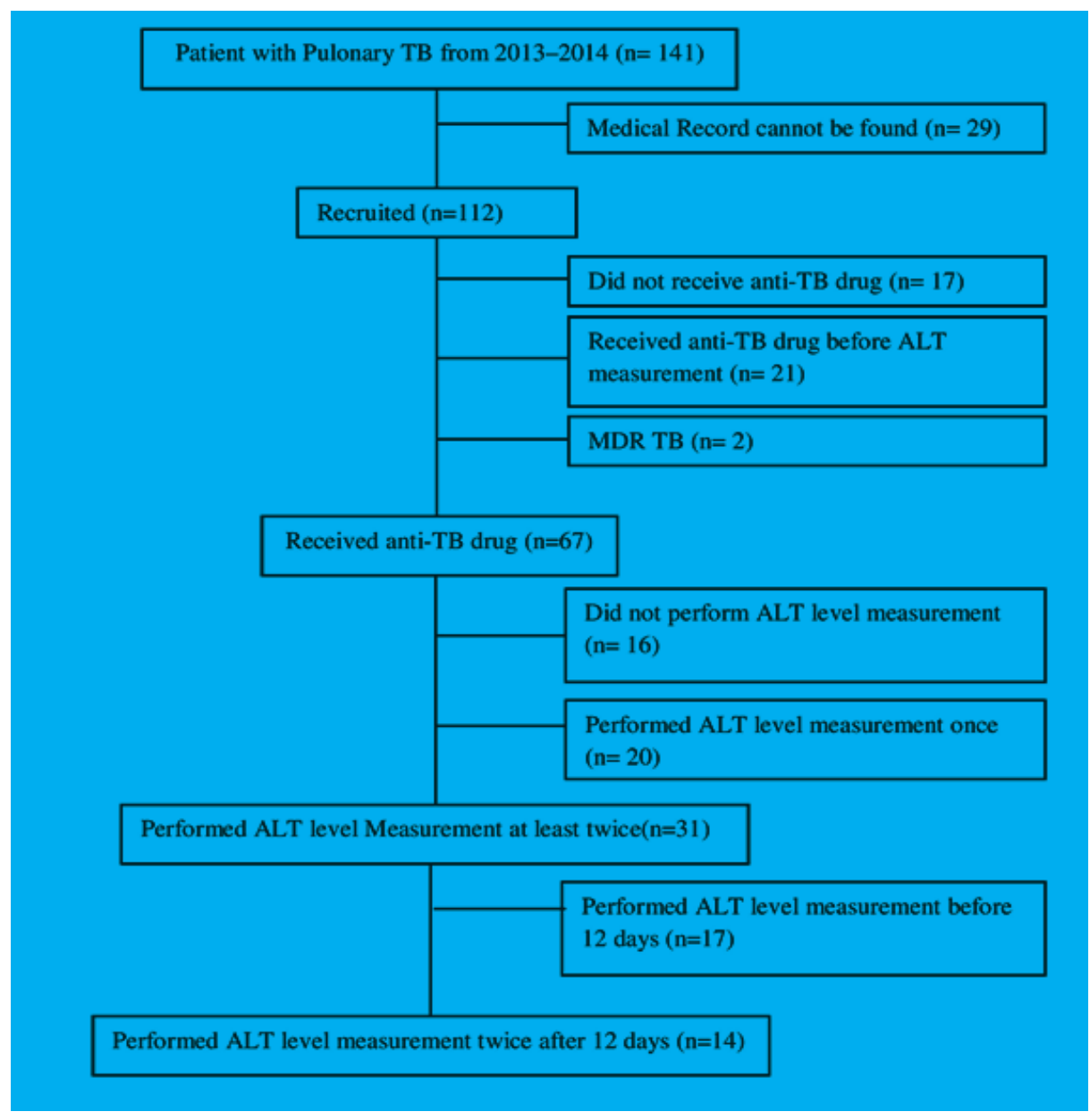

Figure Flow Diagram of All Patients Diagnosed Pulmonary TB in Data 
The results of ALT level measurement in this study were classified into several classes based on Common Terminology Criteria for Adverse Effect (CTCAE) for descriptive purposes. Grade 1 was defined as the increasing of ALT from the highest normal range of ALT until 3 times highest normal level. Grade 2 was defined as the increasing of 3-5 times from highest normal range of ALT level. Grade 3 was defined as the increasing 5-20 times from the highest normal range of ALT. Grade 4 was defined as increasing more than 20 times from the highest normal range of ALT.

Furthermore, ALT level data from the medical record were statistically analyzed using Wilcoxon non-parametric test since there were anomalies in the distribution of data. Statistically significant was considered when $\mathrm{p}<0.05$.

\section{Results}

Among 141 patient's medical records, only 14 met the inclusion criteria and were eligible to be included in this study (Figure 1).

Based on the characteristics of the patients, out of the 14 medical records, 5 developed

Table 1 Baseline Characteristics of 14 pulmonary TB patients included in the study

\begin{tabular}{lc}
\hline \multicolumn{1}{c}{ Characteristics } & $\mathbf{N}$ \\
\hline Age (years): median(minimum-maximum)) & $48(18-65)$ \\
Sex & \\
Male & $6 / 14$ \\
Female & $8 / 14$ \\
Hepatotoxicity & \\
Grade 1 & $4 / 14$ \\
Grade 2 & - \\
Grade 3 & - \\
Grade 4 & $1 / 14$ \\
Co-morbid of pulmonary tuberculosis patients & \\
Extrapulmonary tuberculosis & $2 / 14$ \\
Hematoimmunology disturbances & \\
$\quad$ Human Immunodeficiency Virus Infection & $2 / 14$ \\
Systemic Lupus Erythematosus & $1 / 14$ \\
$\quad$ Toxic Epidermal Necrolysis & $1 / 14$ \\
$\quad$ Thrombocytosis & $1 / 14$ \\
$\quad$ Anemia Inflammation & $2 / 14$ \\
Hemostasis disturbance & \\
Hypertension & $2 / 14$ \\
Pleural effusion & $1 / 14$ \\
Metabolism disturbance (Diabetes Mellitus) & $2 / 14$ \\
Others & $10 / 14$ \\
Co-medication of pulmonary tuberculosis patients & \\
Antidepresants & $2 / 14$ \\
Anticoagulants & $1 / 14$ \\
Antiretrovirals (ARV) & $2 / 14$ \\
Steroids & $4 / 14$ \\
Non Steroidal Anti Inflammatory Drugs (NSAID) & $6 / 14$ \\
\hline
\end{tabular}


Table 2 Comparison of Median of ALT level before and after initial treatment

\begin{tabular}{lcccc}
\hline Variable & Type of test & N & Median (Minimun-maximum) & $P$ \\
\hline \multirow{2}{*}{ ALT (U/L) } & Pre-treatment & 14 & $22(4-447)$ & $0.660^{*}$ \\
& Post-treatment & 14 & $18.5(4-1206)$ & \\
\hline
\end{tabular}

Note: * Tested with nonparametric Wilcoxon test

hepatotoxicity with one of them having severe hepatotoxicity (grade 4). The 14 medical records of pulmonary tuberculosis patients showed that the patients had comorbid disease, the highest co-morbid was hematoimmunology disturbances and the most co-medication used was NSAID (Table 1).

Furthermore, the analysis of pulmonary TB patient's ALT from the measurement before treatment and 12 days after initial treatment used the Wilcoxon test as nonparametric test analysis, and showed there was no significant difference $(p \geq 0,05)$ from the ALT measurement before anti-TB drugs treatment and 12 days after initial treatment (Table 2).

\section{Discussions}

This study showed that the median and mode age of pulmonary tuberculosis patients was 48 and 47 with higher occurrences in female (8/14). This result was similar with another study conducted by Qureshi D et al. ${ }^{7}$, who discovered that the most frequent patients are in the age group of 41-50 years with higher incidence occured in female (71\%). This result occurred because the increasing age was associated with the higher incidence of tuberculosis. ${ }^{8}$ Female subjects was higher than male perhaps due to several specific conditions in female, such as malnutrition, pregnancy, breastfeeding baby, and socioeconomic conditions. ${ }^{9}$

In addition, co-medication recorded along with anti-TB drug in this study was NSAID. Eventhough this data was not related to the high event of hepatotoxicity, one study discovered that overdose of NSAID, especially acetaminophen, could cause liver damage. The liver damage is caused by the metabolite (NABQI) of the drug produced by the cytochrome P-450 enzymes in the liver. This metabolite could lead cell death and hepatocelullar necrosis. ${ }^{5}$

In this study, the range of ALT measurement before anti-TB treatment was 4-477 U/L. It was discovered that one of the subjects had a very high ALT level (447 U/L). It might occur since the subject had Human Immunodeficiency
Virus (HIV) infection and consumed ARV drugs. These drugs are one of the most drugs that could cause hepatotoxicity. The mechanism of hepatotoxicity caused by ARV can be due to direct toxicity to the hepatocyte, hypersensitivity reaction, or mitochondrial activity. ${ }^{7}$ The second ALT level measurement's result of this patient revealed the deceasing ALT level (60U/L).

Another result in this study revealed that the range of ALT measurement on 12 days after initial therapy was 4-1206 U/L. The subject who had the highest ALT measurement in this period only took an anti-TB therapy according to the hospital medical records. The baseline of ALT level was normal (26 U/L) and increased 17 days after the initial therapy become 1206 U/L (hepatotoxicity grade 4). This subject could be classifiied as severe hepatotoxicity since the third examination revealed that the ALT level decreased although did not reach the normal range. It was similar with the study conducted by Gulbay et al. $^{10}$, who discovered that the incidence of severe hepatotoxicity is 9 $(0,8 \%)$ out of 1149 subjects.

The current study showed, there was no liver damage based on the ALT level measurement before the anti-TB treatment and 12 days after the initial treatment of antiTB treatment.This study corresponded with a study conducted by Nahar. ${ }^{11}$ It showed that there are also neither alteration of ALT before treatment $(4.85 \pm 2.17) \mathrm{U} / \mathrm{L}$ and 12 days after initial treatment (7.50 56.02$) \mathrm{U} / \mathrm{L}$ nor clinically appreciable. ${ }^{11}$ However, another study by Gulaty et al. $^{12}$, showed there are alteration of ALT before treatment $(18.8 \pm 3.70) \mathrm{U} / \mathrm{L}$ and 12 days after initial treatment $(40.6 \pm 4.20)$ $\mathrm{U} / \mathrm{L}$.This study conducted by Gulaty et al. ${ }^{12}$ is performed through primary data collection, and the increased frequency as compared to our study could be as a result of complete data information.

The changes of ALT in the period of 12 days after initial treatment which did not show alteration could occur possibly as hepatocyte is considered similar to other cells in the human body. Although, hepatotoxicity occurred in this study, it did not reveal a high result due to the 
regeneration of hepatocyte. The regeneration is initiated by the Hepatocyte Growth Factor (HGF) that is released as response to trauma, either due to physical trauma or chemical trauma. This factor activates the antioxidant signaling pathway and it could prevent oxidative stress enhancement which lead to the increasing of ALT. The process of regeneration would start in 5 minutes after trauma and complete the process in 5-7 days. ${ }^{5,13}$

Moreover, ALT enhancement is also determined by a genetic factor, although it could not be used as a conclusion since it could not be obtained from medical records. One of the genes responsible for the anti-TB drugs' metabolism is the $\mathrm{N}$-acetyltransferase-2 (NAT2) gene. The anti-TB drug that is metabolized by this gene is isoniazid. Besides, the NAT-2 gene has a role in the acetylation process of hepatic N-acetyltransferase. Polymorphism of the NAT-2 gene could be different in patients. There are three kinds of NAT-2 genetic variation in humans: slow acetylator, intermediate acetylator, and fast acetylator. These differences include the catalytic activity, stability of enzyme metabolizing by the drug, and the drug affinity. ALT would increase in a person who has slow and fast acetylator status. $^{14}$

The limitation of this study was the missing medical records since the medical record unit did not recorded all the data of inpatient pulmonary TB patients in the Internal Medicine Department of the period $1^{\text {st }}$ January 2013-31 $1^{\text {th }}$ December 2014 which could be analyzed. The remaining medical records also had incomplete information, especially the ALT measurement test result and the onset of anti-TB initial treatment. Expanding the sample study or homogenizing the sample from other sources could be an option to avoid the missing or incomplete information from medical records and to meet the sample size requirement. Besides, the pilot study should be performed to estimate the sample number needed in the study. Moreover, a case control study could be the alternative to reveal the effect of hepatotoxicity caused by anti-TB drugs in the future.

In conclusion, there are no differences of ALT level changes before treatment and 12 days after initial treatment. However, the ALT level should still be checked due to the possibility of the occurrence of hepatotoxicity in this study, and to manage and evaluate the symptom that will occur. Anti-tuberculosis drugs could be the possible or definitive cause of hepatotoxicity. The reaction after discontinuing the drugs should be observed to discover that anti-TB drugs is the definitive cause of hepatotoxicity.

\section{References}

1. Kementrian Kesehatan Republik Indonesia. Pedoman Nasional Penanggulangan Tuberkulosis. Jakarta: Bakti Husada, 2014.

2. World Health Organization. Global Tuberculosis Report 2014. France: WHO, 2015.

3. Sari ID, Yuniar Y, Syaripuddin M. Studi monitoring efek samping obat antituberkulosis fdc kategori 1 di Provinsi Banten dan Provinsi Jawa Barat. Media Litbang. 2014;24(1):28-35.

4. Khoharo HK, Ansari S, Siddiqui AA, Qureshi F. Standard antituberculosis drug induced hepatotoxicity : do the risk factors matter. J Liaquat Univ Med Heal Sci. 2010;09(2):847.

5. Singh A, Bhat TK, Sharma OP. Clinical biochemistry of hepatotoxicity. J Clin Toxicol. 2011;1(3):1-19

6. Mahmood K, Hussain A, Jairamani KL. Hepatotoxicity with antituberculosis drugs: the risk factors. Pak J Med Sci. 2007;23(1):33-8.

7. Núñez M. Hepatotoxicity of antiretrovirals: incidence, mechanisms and management. J Hepatol. 2006;44(1 Suppl):S132-9.

8. Wang C-S, Chen H-C, Yang C-J, Tsai J-R, Chong I-W, Hwang J-J, et al. Clinical characteristics of pulmonary tuberculosis patients from a southern Taiwan hospitalbased survey. Kaohsiung J Med Sci. 2008;24(1):17-24.

9. Abbasi A, Moradi A, Kabir, MJ. Characteristic of Pulmonary Tuberculosis Patients in Golestan Province of Iran, 2002-2005. J Med Sci. 2006;6(4):698-700.

10. Gülbay BE, Gürkan ÖU, Yildiz ÖA, Önen ZP, Erkekol FO, Baççioğlu A, et al. Side effects due to primary antituberculosis drugs during the initial phase of therapy in 1149 hospitalized patients for tuberculosis. Respir Med. 2006;100(10):1834-42.

11. Nahar BL, Hossain AM, Islam MM, Saha DR. A comparative study on the adverse effects of two anti-tuberculosis drugs regimen in initial two-month treatment period. Bangladesh J Pharmacol. 2008;1(2):51-7.

12. Gulati K, Ray A, Vijayan VK. Assessment of protective role of polyherbal preparation, Livina, against anti-tubercular drug induced liver dysfunction. Indian J Exp Biol. 2010;48(3):318-22.

13. Enriquez-Cortina C, Almonte-Becerril M, 
Vera Dianwari, Vycke Yunivita Kusumah Dewi, Nia Kania: Effect of Anti-tuberculosis Drugs on Liver Damage 511 Based on Alanine Aminotransferase Level in Pulmonary Tuberculosis Patients

Clavijo-Cornejo D, Palestino-Dominguez M, Bello-Monroy O, Nuno N, et al. Hepatocyte growth factor protects against isoniazid/ rifampicin-induced oxidative liver damage. Toxicol Sci. 2013;135(1):26-36.
14. Kumar AKH, Sudha V, Ramachandram G. Simple and rapid method for simultaneous determination of isoniazid and acetyl isoniazid in urine by HPLC. Asian J Biomed Pharm Sci. 2014;4(34):46-50. 